\title{
Political swings and roundabouts
}

\author{
With a politically tumultuous spring and the window on keeping global average temperatures below $2^{\circ} \mathrm{C}$ \\ above preindustrial levels closing, environmental advocacy perhaps has a more important role now than \\ ever before.
}

It's been an eventful start to 2017 from a climate policy perspective, with several of the major upheavals in politics from last year beginning to filter through into the climate policy domain. The announcement of Donald Trump's America First budget proposal $^{1}$ in mid-March showed his intention to cut nearly a third of the US Environmental Protection Agency's (EPA) budget. The Office of Research and Development was picked out to suffer even more severely with an almost 50\% cut to its budget, which would inevitably impact upon international as well as US domestic climate work. This was a powerful statement of intent and firmly established the administration's anti-environmental regulation stance. Further to this, the Presidential Executive Order on Promoting Energy Independence and Economic Growth ${ }^{2}$ quickly followed and is set to reverse many Obama-era rules designed to restrict US greenhouse-gas emissions.

Hot on the heels of these developments came two more initiatives - one to alter the criteria for who can serve on the EPA's scientific advisory committee ${ }^{3}$, and the other the HONEST Act ${ }^{4}$ that alters the criteria for what science the EPA is permitted to use to support new regulations. Although presented as reforms to improve the function of the EPA, many feel that the legislation is rather designed to reduce the power and capacity of the EPA to do its work 5 .

The HONEST Act "requires that [the] EPA base its regulations and assessments on the 'best available science' that is publicly available in a manner sufficient for independent analysis and scientific replication". There are some exemptions for personally identifiable information, trade secrets and so on. The implications for which scientific papers will, and will not, be eligible for use to support policy will depend to some extent on how some of these phrases are interpreted. For example might 'publically available' require fully open access licencing under a creative commons license? Such a requirement would be a huge boost to open-access publishing and its advocates, but would exclude a great deal of the available science from the policy sphere in the US. However this does seem unlikely and green open access - the practice of depositing articles on institutional websites, online repositories or similar sites, at publication or after a short embargo - would seem to satisfy these requirements.

Perhaps the bigger question mark hovering over the act is what would qualify as replication. Many datasets are essentially not reproducible in practice: consider satellite data for a given period, or experiments over extended periods of time that are financially and logistically prohibitive to repeat. So perhaps only the data analysis must be replicated - but then to what degree of similarity must the findings correspond? Indeed, politically controversial findings that have repeatedly passed the test of replication, and moreover verification using alternative methods, have remained contested at a political level: the 'hockey stick' graph - showing how high recent temperatures are compared with the past 2,000 years - is perhaps an exemplar.

Clearly there is no simple catch-all answer for what represents scientific replication, particularly as science in general is going through something of a crisis about the rate of reproducibility of published papers (see for example ref. 6). Such ambiguities would seem to leave the door open to delay and debate over any new environmental legislation in the US, something that is particularly challenging in a political environment starting from the presumption that less environmental legislation is better. It's hard to imagine economic or military policy being able to function under a similar level of scrutiny of the evidence used to support decision-making.

Some different political waves are emerging from across the Atlantic as the United Kingdom formally triggered Article 50 on 29 March 2017 - beginning a two-year countdown to its departure from the EU. This does not represent the kind of swing in attitudes towards climate change that the Obama-Trump transition has witnessed, but clearly there will be many strategic priorities for both the United Kingdom and Europe, most prominently trade negotiations, which may eclipse climate policy development and implementation over this critical period following Paris.

With these various political landslips intruding into climate policy and its implementation at such a critical juncture for climate mitigation efforts, the environment has probably never been more in need of championing even if we need to think carefully about how that is done (see for example our January editorial ${ }^{8}$ ). One of the more prominent events in the environmental lobbying calendar this year, Earth Day (22 April 2017), had a focus on environmental and climate literacy. To mark the occasion, Nature Research has posted a number of blogs, hosted on the Nature Ecology \& Evolution community site (http://go.nature.com/2olatr6). As well as an Editor's pick of Nature Research published papers across Earth science and climate change from the last year or so, there are contributions from the Nature Climate Change editorial team, including discussion of climate change MOOCs (massive open online courses) and a piece promoting wider interest in science. We hope these are useful and informative. Environmental advocacy and education at this politically tumultuous time is certainly needed to keep the climate and environment front and centre in the minds of the public and their politicians.

\footnotetext{
References

1. America First: a Budget Blueprint to Make America Great Again (Executive Office of the President of the United States, 2017).

2. Presidential Executive Order on Promoting Energy Independence and Economic Growth (The White House, 2017).

3. EPA Science Advisory Board Reform Act of 2017 H.R.1431 (The Senate of the United States, 2017).

4. HONEST Act H.R.1430 (The Senate of the United States, 2017)

5. Rosenberg, A. House bills would undermine science, cripple public health and safety protections. Union of Concerned Scientists (28 March 2017)

6. Baker, M. Nature 533, 452-454 (2016).

7. Climate Change Act 2008 (Parliment of the United Kingdom, 2008). 8. Nat. Clim. Change 7, 1 (2017).
} 